\title{
Pelatihan Pembuatan Tumpeng Upakara sebagai Upaya Peningkatan Omset UKM Adi Upakara
}

\author{
1* I Nyoman Tri Anindia Putra, ${ }^{2}$ Ketut Sepdyana Kartini, ${ }^{3}$ Luh Gede Kusuma Dewi \\ STMIK STIKOM Indonesia ${ }^{1}$, STMIK STIKOM Indonesia ${ }^{2}$, Universitas Pendidikan Ganesha ${ }^{3}$ \\ *Email: trianindiaputra@gmail.com
}

\begin{abstract}
ABSTRAK
Pengabdian Masyarakat ini bertujuan untuk meningkatkan omset bulanan mitra Usaha Kecil Menengah (UKM) di Banjar Pondok Kelod, Desa Gadungan Kecamatan Selemadeg Timur. UKM yang bergerak di bidang pembuatan upakara, dalam proses produksinya sangat di pengaruhi oleh banyak sedikitnya hari perayaan Agama Hindu. Pengabdian masyarakat ini bertujuan untuk meningkatkan omset mitra, yakni dengan memberikan pelatihan pembuatan tumpeng upakara. Materi pelatihan yang diberikan meliputi, bahan-bahan untuk pembuatan tumpeng, cara pembuatan tumpeng, serta pengemasan hingga pemasaran. Berdasarkan hasil penilaian pre-test terkait pemahaman awal mitra cara produksi tumpeng upakara hingga pengemasan yang siap dipasarkan masih tergolong rendah, yang mana rata-rata nilai pre-test dalam mengetahui bahan-bahan pembuatan tumpeng 45,55\%, pembuatan tumpeng upakara $25,56 \%$ dan pengemasan serta pemasaran $35,45 \%$. Terlaksananya pelatihan pembuatan tumpeng upakara membuat mitra menjadi paham tahapan pembuatan hingga dihasilkan tumpeng yang siap dikemas dengan nilai post-test mengetahui bahan-bahan pembuatan tumpeng $92,55 \%$, pembuatan tumpeng upakara $85,56 \%$ dan pengemasan serta pemasaran $75,45 \%$. Hal ini menunjukkan bahwa dengan diadakannya pengabdian terkait pelatihan pembuatan tumpeng upakara, mampu memberikan keterampilan baru terhadap mitra dan omset bulanan mitra meningkat sebesar $87,29 \%$.
\end{abstract}

Kata kunci: Omset, Tumpeng Upakara, PKM, Pelatihan

\section{ABSTRACT}

This Community Service aims to increase the monthly turnover of Small and Medium Enterprises (UKM) partners in Banjar Pondok Kelod, Gadungan Village, East Selemadeg District. UKM which is engaged in the manufacturing of ceremonies, in the process of its production is greatly influenced by many or at least Hindu religious holidays. The community service was conducted in order to increase partner turnover by providing training on making Tumpeng Upakara. The training materials provided include materials for making cones, how to make cones, and packaging to marketing. Based on the results of the pre-test assessment related to the initial understanding of partners how to produce upakara cone until the packaging is ready to be marketed is still relatively low, where the average value of the pretest in knowing the ingredients of cone making 45.55\%, making cone upakara 25, 56\% and packaging and marketing $35.45 \%$. With the training on making upakara cone, partners 
become aware of the stages of making up to produce cone ready to pack with the post-test value knowing the ingredients of cone making 92.55\%, making cone upakara $85.56 \%$ and packaging and marketing $75.45 \%$. This shows that the holding of services related to the training of making Tumpeng upakara is able to provide new skills to partners and the monthly turnover of partners increases by $87,29 \%$.

Key words: Turnover, Tumpeng Upakara, Training

\section{PENDAHULUAN}

Kementerian Koperasi dan Usaha Menengah Kecil dan Mikro (UMKM) terus berusaha mengembangkan usaha sektor riil yang menjadi penggerak ekonomi indonesia (Utama, 2017). salah satunya adalah UMKM/UKM yang bergerak di bidang penjualan banten. Upakara atau bebantenan merupakan salah satu sarana dalam rangkaian pelaksanaan suatu upacara keagamaan (Suantini, 2007). Upakara atau banten merupakan perwujudan dan ajaran bhakti marga dan karma marga (Sri,2018).

Fenomena penjualan produk-produk upakara semakin menjamur di kalangan masyarakat. Hal ini terjadi karena tingginya permintaan karena aktivitas masyarakat bali khususnya wanita Bali banyak yang bekerja di luar rumah. Di jaman yang modern dan praktis ini, wanita Bali lebih memilih membeli perlengkapan upakara yang sudah jadi (Damayana, 2011). Secara ekonomi, adanya permintaan ini memberikan peluang usaha baru bagi masyarakat Bali. Desa Gadungan Kecamatan Selemadeg Timur terdapat kelompok Usaha Kecil Menengah (UKM) yang bergerak di bidang pembuatan upakara. Usaha ini sudah dijalani sejak tahun 2010 oleh ibu Wayan Renten selaku pemilik usaha.

Pengembangan produk dan inovasi merupakan sebuah hal penting yang dibutuhkan oleh perusahaan (Wijaya, 2013). salah satunya dengan cara mengasah kreativitas, hal ini sangat diperlukan karena pentingnya bagi keberhasilan kita dalam menciptakan peluang usaha (Sari, 2013). Melihat peluang pasar saat ini, mitra bisa mengembangkan keterampilan dalam penjualan perlengkapan upakara, guna meningkatkan omset penjualan mitra. Salah satunya memproduksi tumpeng upakara yang merupakan sarana perlengkapan upakaral banten yang banyak digunakan sebagai pelengkap berbagai jenis banten.

Tabel 1. Analisis Situasi

\begin{tabular}{|l|l|l|l|}
\hline No & Bidang & $\begin{array}{l}\text { Permas } \\
\text { alahan }\end{array}$ & Solusi \\
\hline 1 & Ekonomi & $\begin{array}{l}\text { Kurang } \\
\text { nya } \\
\text { omset } \\
\text { penjual } \\
\text { an pada } \\
\text { mitra }\end{array}$ & $\begin{array}{l}\text { Pelatihan } \\
\text { Pembuatan } \\
\text { Tumpeng } \\
\text { Upakara } \\
\text { Sebagai } \\
\text { produk jual } \\
\text { untuk } \\
\text { meningkatk } \\
\text { an omset } \\
\text { penjualan }\end{array}$ \\
\hline
\end{tabular}




\begin{tabular}{|c|c|c|c|}
\hline 2 & $\begin{array}{l}\text { Marketin } \\
\mathrm{g}\end{array}$ & $\begin{array}{l}\text { Kurang } \\
\text { nya } \\
\text { pemaha } \\
\text { man } \\
\text { terkait } \\
\text { pemasa } \\
\text { ran } \\
\text { dalam } \\
\text { penjual } \\
\text { an } \\
\text { produk }\end{array}$ & $\begin{array}{l}\text { Membantu } \\
\text { merancang } \\
\text { kemasan } \\
\text { produk } \\
\text { serta } \\
\text { pembuatan } \\
\text { logo } \\
\text { produk. }\end{array}$ \\
\hline
\end{tabular}

Berdasarkan Tabel 1, dapat dilihat bahwa kurangnya omset bulanan penjualan mitra ketika tidak mendapatkan orderan. Hal ini dikarenakan produksi upakara masih bersifat musiman, dalam arti masih dipengaruhi oleh hari baik dalam menentukan upacara keagamaan serta hari raya Agama Hindu yang telah disesuaikan dengan kalender Bali. Jadi jika dalam beberapa bulan jumlah hari raya di Bali tidak terlalu banyak, maka produksi upakara menurun bahkan tidak melakukan produksi. Untuk meningkatkan omset mitra melihat dari peluang pasar yang ada. Yang mana, di desa gadungan belum ada pedagang yang menjual tumpeng upakara sehingga hal ini sangat berpeluang besar dalam penjualan perlengkapan upakara. Selain itu, mitra juga memiliki masalah dari segi pemasaran. Kami memberikan pelatihan pemasaran produk dan juga pengemasan produk di sertai dengan pembuatan logo usaha mitra untuk menjadi ciri khas produk mitra.

\section{RUMUSAN MASALAH}

Adapun rumusan masalah dalam kegiatan pengabdian masyarakat yaitu:

Masalah : omset bulanan yang tidak tetap atau bahkan tidak ada pemasukan sama sekali.
Solusi : memberikan pelatihan pembuatan tumpeng upakara

Indikator : pembuatan tumpeng upakara, pengemasan dan pemasaran

\section{METODE}

Identifikasi persoalan diperoleh melalui observasi dan wawancara (Muslimin, 2009). Banyak metode penelitian yang dapat digunakan dalam menunjang penelitian, seperti metode penelitian deskriptif. Metode deskriptif yaitu suatu bentuk penelitian yang ditujukan untuk mendeskripsikan fenomena-fenomena yang ada, baik fenomena alamiah maupun fenomena buatan manusia (Safrijal, 2016). Metode yang diterapkan dalam pelaksanaan pengabdian masyarakat ini adalah pelatihan. Pelatihan yang dilakukan yaitu pelatihan pembuatan tumpeng upakara yang dimulai dari pengenalan bahanbahan, cara pembuatan dan pengemasan serta pemasaran tumpeng upakara.

\section{PEMBAHASAN}

Adapun kegiatan pengabdian yang telah dilaksanakan selama 2 bulan dari 4 Juli 2019- 12 September 2019 yaitu:

1) Sosialisasi

Tahap pertama yang dilakukan adalah sosialisasi dan koordinasi terkait program pelaksanaan kegiatan pengabdian masyarakat. Tahap ini ketua pengusul memberikan pengarahan terkait latar belakang kegiatan, target dan tujuan kegiatan, serta membuat kesepakatan bersama terkait waktu pelaksanaan kegiatan pengabdian tersebut.

2) Pelatihan Pembuatan Tumpeng Upakara 
Kegiatan pelatihan pembuatan tumpeng upakara dimulai dengan pengenalan bahan-bahan yang digunakan sebagai bahan dasar, membuat alat cetakan tumpeng upakara dan mengeringkan tumpeng dengan baik agar tidak mudah berjamur dalam kemasan. Kegiatan pelatihan ini dilaksanakan $3 \mathrm{x}$ pertemuan dengan 1 bulan pendampingan. Adapun gambar proses kegiatan yang dapat dilihat pada Gambar 1.

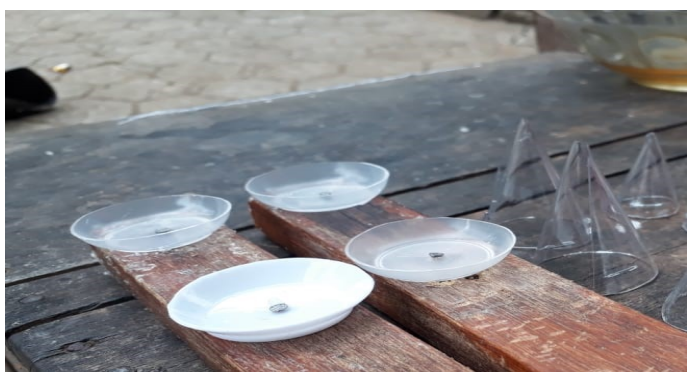

(a) alat cetak tumpeng upakara

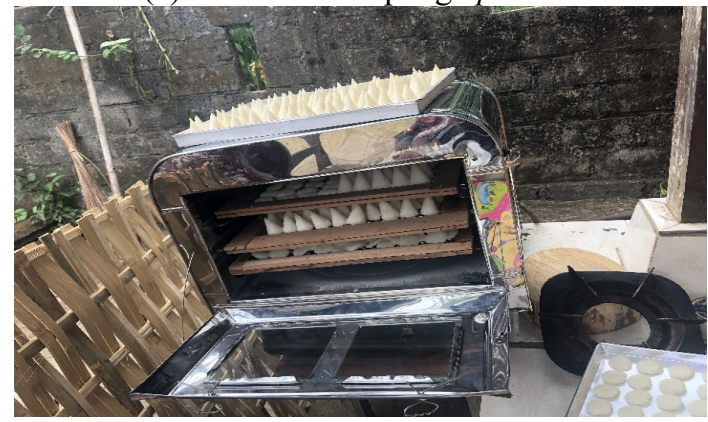

(b) alat pemanggangan tumpeng upakara

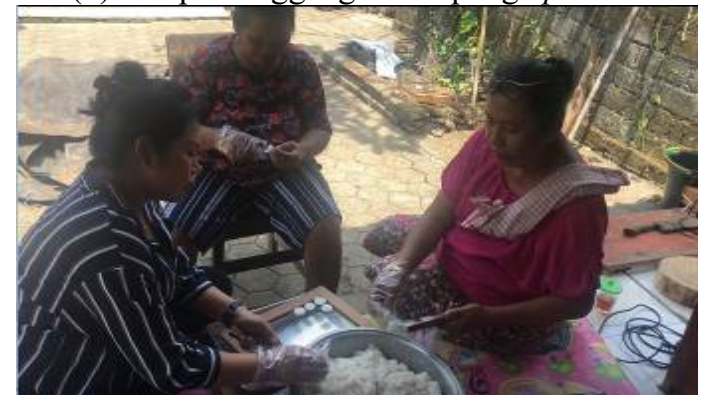

(c) proses pencetakan Tumpeng Upakara Gambar 1. Proses Pembuatan Tumpeng Upakara
3) Pelatihan Pengemasan Tumpeng Upakara

Tumpeng upakara yang selesai di produksi dikemas dengan rapi agar menarik minat pembeli. Serta diberikan logo UKM sebagai ciri khas mitra.

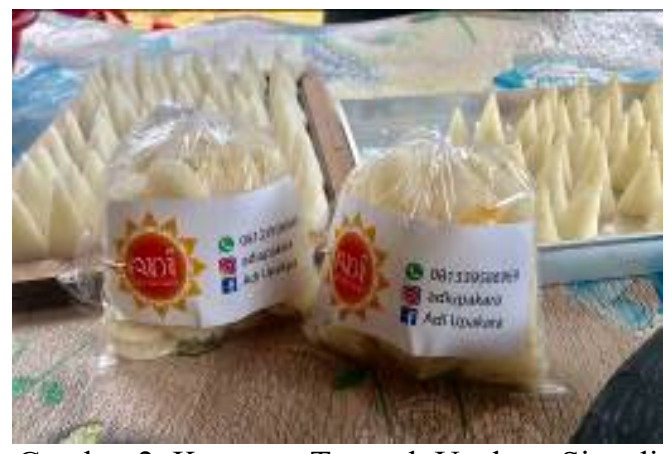

Gambar 2. Kemasan Tumpek Upakara Siap di pasarkan

4) Pelatihan Pemasaran Tumpeng Tumpeng Upakara yang sudah di kemas, siap dipasarkan ke warungwarung di sekitar desa dan di luar desa, serta pasar tradisional

Kegiatan yang telah dilakukan adalah kegiatan untuk menambah keterampilan mitra terkait usaha yang telah dilakukan guna meningkatkan omset dari mitra ketika mitra tidak mendapat orderan pembuatan upakara. Kegiatan tersebut adalah kegiatan pelatihan keterampilan terhadap mitra dalam membuat produk baru bagi mitra untuk membuat tumpeng upakara sebagai sarana pelengkap dalam pembuatan banten/ upakara yang banyak dicari di setiap pasar utamanya di Bali. Berdasarkan observasi yang telah dilakukan belum banyak penjual yang menjual tumpeng upakara sehingga hal tersebut menjadi acuan bagi pelaksana PKM untuk memberikan pelatihan terkait pembuatan tumpeng upakara. Pelatihan tersebut meliputi proses awal pembuatan 
tumpeng sampai pada pengemasan tumpeng sehingga siap untuk dijual.

Hasil evaluasi dan monitoring menunjukkan pelatihan kegiatan pembuatan tumpeng upakara telah berhasil dilaksanakan dan mitra memiliki omset tetap tiap bulannya dan meningkat. Adapun grafik perkembangan mitra sebelum dan sesudah dilakukan kegiatan PKM sebagai berikut.

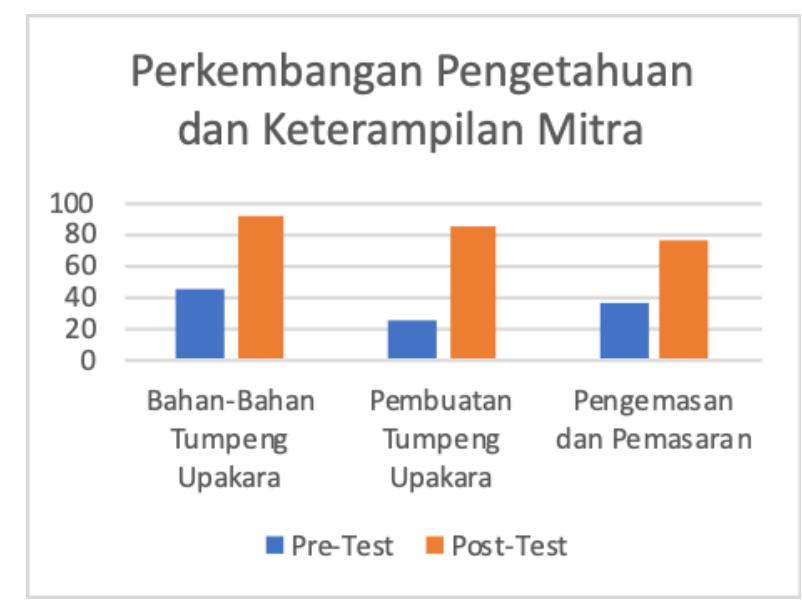

Gambar 3. Hasil Pre-test dan Post-test

Gambar 3 menunjukkan peningkatan dari pre-test ke post-test. Rata- rata nilai pretest dalam mengetahui bahan-bahan pembuatan tumpeng $45,55 \%$, pembuatan tumpeng upakara $25,56 \%$ dan pengemasan serta pemasaran $35,45 \%$. Sementara, posttest untuk mengetahui bahan-bahan pembuatan tumpeng $92,55 \%$, pembuatan tumpeng upakara $85,56 \%$ dan pengemasan serta pemasaran $75,45 \%$. Hal ini menunjukkan bahwa pelatihan PKM, mampu meningkatkan kemampuan mitra dalam memproduksi tumpeng upakara sampai menjadi prodak yang layak untuk di pasarkan. Adanya keterampilan baru yang dimiliki oleh mitra merupakan sumber pendapatan baru bagi mitra. Di saat mitra tidak mendapatkan orderan upakara, mitra dan anggota dapat memproduksi tumpeng upakara dan memasarkannya. Dari hasil menjual tumpeng upakara, mitra memiliki omset usaha perbulannya bahkan meningkat dari sebelum diadakannya pelatihan pembuatan tumpeng upakara. Berikut grafik perkembangan omset mitra sebelum diadakan pelatihan dan sesudah diadakan pelatihan dapat dilihat pada Gambar 4.

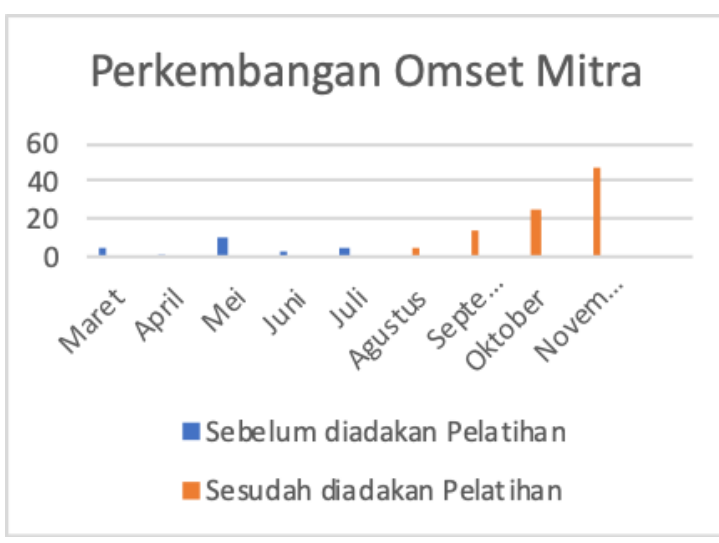

Gambar 4. Grafik Perkembangan Omset Mitra

Berdasarkan Gambar 4, dapat di lihat adanya kenaikan omset mitra setelah diadakan pelatihan pembuatan tumpeng upakara. Omset bulanan mitra meningkat sebesar $87,29 \% \%$, yang mana sebelum diadakan pelatihan omset mitra di 1,5 juta3 juta rupiah. Setelah diadakan pelatihan mitra memiliki omset bulanan tetap bekisar 4juta-8juta rupiah.

\section{SIMPULAN}

Berdasarkan hasil dari pelatihan pembuatan dan pemasaran tumpeng upakara, mitra memiliki keterampilan baru terkait produksi tumpeng upakara. Pelatihan pembuatan tumpeng upakara berdampak pada peningkatan pengetahuan dan keterampilan mitra dalam pembuatan hingga dihasilkan tumpeng yang siap dipasarkan. Hasil pre-test dan post-test menunjukkan pengetahuan mitra terkait bahan-bahan pembuatan tumpeng 
meningkat $47 \%$, pembuatan tumpeng upakara $60 \%$ dan pengemasan serta pemasaran Adanya keterampilan baru dalam membuat tumpeng upakara, mitra memiliki prodak baru yang sudah siap di pasarkan, sehingga omset bulanan mitra mengalami peningkatan.

\section{UCAPAN TERIMA KASIH}

Ucapan terima kasih sebesar besarnya ditujukan kepada :

1. Kementerian Riset dan Teknologi / Badan Riset dan Inovasi Nasional Republik Indonesia.

2. Mitra UKM Adi Upakara

3. Jurnal Ilmiah Populer Widyabhakti

4. Seluruh Pihak yang mendukung terlaksananya kegiatan pengabdian kepada masyarakat sehingga dapat berjalan dengan baik, serta kepada pihak yang memberikan gagasan, saran, masukan serta pandangan terhadap penyusunan artikel pengabdian ini.

\section{DAFTAR PUSTAKA}

Damayana, I.W. 2011. Menyama Braya.

Studi Perubahan Masyarakat Bali.

Fakultas Teologi, Universitas

Kristen Satya Wacana

Muslimin, L., Wicaksena, B., Setiyawan, B., Subekti, N. A., Sukesi, H., Surachman, H., Khaidir, K. (2009). Kajian potensi pengembangan pasar jamu. Jakarta.
Sari, Debi Olivia. 2013. Pelatihan Kerajinan Tangan Dari Kain Flanel Sebagai Pemberdayaan . Jurnal Inovasi dan Kewirausahaan . Volume 2 No. 2, Mei 2013

Sri Mulyani, Nyoman. 2018. Prospek Bisnis Banten : Upaya Mengurangi Mental Konsumtif dan Kemiskinan di Bali. PURWADITA, 1(1): 64-70

Suantini, Ida Ayu. 2007. Pemodelan Sistem Bebantenan ditinjau dari Jenis-jenis Banten dan Perlengkapannya. Skripsi Teknik Elektro UNUD,Bali.

Utama, A. A. G. S., \& Pratama, D. (2017). Pengabdian masyarakat Desa Taman Sari: Optimalisasi kinerja UMKM melalui pelatihan akuntansi sederhana. In Seminar Nasional Hasil Penelitian dan Pengabdian kepada Masyarakat UNIPMA (pp. 357-360). Madiun: UNIPMA. Retrieved from https://semnas.unikama.ac.id/lppm/ prosiding/2017/Pengabdian/45.Ray mond_Nanik_Pengabdian_Ekonom i_dan_bisnis.pdf

Wijaya, Wirawan Surya, 2013. Analisis Pengembangan Produk pada Perusahaan Tepung Terigu di Surabaya. Jurnal Agora Vol. 1, No.1, (2013) 